\title{
A COMPOSIÇÃO ORIGINAL PARA VOZES INFANTIS E INFANTO-JUVENIS E SUAS INTERFACES COM A CONTEMPORANEIDADE, TRADIÇÃO E A LITERATURA POPULAR E NEOFOLCLÓRICA
}

\section{THE ORIGINAL COMPOSITION FOR CHILDREN'S AND JUVENILE'S VOICES AND ITS INTERFACES WITH CONTEMPORANEITY, TRADITION AND THE NEO-FOLKLORIC LITERATURE}

\author{
Silvia Maria Pires Cabrera Berg \\ Universidade de São Paulo \\ silviberg@usp.br
}

\begin{abstract}
Resumo
O desenvolvimento do canto coral como instrumento essencial na área de Educação Musical faz com que se tornem necessárias as investigações sobre a produção de materiais didático-pedagógicos para o ensino básico, médio e avançado do canto coral como ferramenta para a educação musical de crianças e jovens. A demanda por materiais pedagógicos que sejam alinhados às crescentes pesquisas nas áreas de técnica vocal infantil, partindo da interação das áreas teórico e performáticas com as áreas da educação musical, apontam a necessidade de projetos integrados em composição, interpretação, execução, pesquisa e educação musical. Partindo das propostas de Émile Jaques-Dalcroze ( 1865 - 1950) e Zoltán Kodály (1 882-1967), Boysen e Enevold, pretende-se neste artigo fazer um levantamento para a produção de tais materiais, assim como da adaptação de materiais existentes, e a composição de materiais originais que contemplem as atividades de ensino, pesquisa e extensão nas três grandes áreas da música e suas respectivas interfaces e interdisciplinaridades: composi-
\end{abstract}


ção, interpretação/execução e pesquisa.

Palavras-chave: canto coral; educação musical; sociedades complexas; composições originais para voz

\begin{abstract}
The development of choral singing as an essential tool in the field of Music Education makes necessary the investigations on the production didactic-pedagogical teaching materials for basic, médium and advanced choral singing as a tool for music education of children and Young people. The demand for instructional materials that are aligned with the growing research in the areas of children vocal technique, based on the interaction of theoretical and performative areas with the areas of music education, highlight the need for integrated projects in composition, performance, research and music education. Based on the proposals of Émile Jaques-Dalcroze (1865-1950) Zoltán Kodály (18821967), and Boysen E Enevold, this paper aims a survey for the production of such materials, as well as the adaptation of existing materials, the composition of original compositions addred the musical teaching, research in the three major areas of music and their interfaces and interdisciplinarity: composition, interpretation / performance and research.
\end{abstract}

Keywords: choral singing; music education; complex societies; original compositions for voices

\title{
Introdução
}

Este artigo faz parte das pesquisas realizadas por um projeto acadêmico de intercâmbio internacional entre Børnekorakademiet (Dinamarca) sob a coordenação de Pia Boysen e o Departamento de Música da FFCLRP da Universidade de São Paulo sob a coordenação de Silvia Berg, que visa contribuir para o desenvolvimento de concei- 
tos, metodologias e materiais para o aprimoramento do conhecimento da voz infantil e infanto-juvenil, estudos de processos de preparação vocal, ensaio e performance em corais infantil e infanto-juvenis e preparação de materiais adequados a tais estudos com literatura e composições em português. Do material que vem sendo produzido dentro deste projeto constam composições originais que serão publicadas juntamente com a tradução da metodologia desenvolvida por Boysen e Enevold como parte do Acordo Acadêmico Internacional firmado por Børnekorakademiet', Dinamarca, e o Departamento de Música da FFCLRP-USP.

A pesquisa que vem sendo desenvolvida é direcionada ao desenvolvimento de ferramentas técnicas cuja aplicabilidade possa ser absorvida tanto em localidades sem ou com poucos recursos econômicos, como outras de maior poder aquisitivo, mas que, sob qualquer circunstância, possam propiciar um ensino e práticas musicais visando a excelência ${ }^{2} \bigcirc$ projeto contempla ainda a composição de canções com texto em português tanto de obras originais para vozes infantis e infanto-juvenis como de arranjos que tenham sido escritos observando a tessitura e registros de vozes infantis em diferentes faixas etárias que sejam adequadas como materiais didático-pedagógicos.

Dentro dos objetivos deste projeto constam:

1 - Contribuir para a formação profissional da Educação Musical que atuem na interseção e fusão dos conhecimentos da Composição, Interpretação-execução e Pesquisa, tendo a complexidade e a excelência como fundamento.

2 - Contribuir para o desenvolvimento de conceitos, metodolo-

\footnotetext{
I Børnekorakademiet - www.bornekorakademiet.dk (acessado em 16.12.20 15).

2 Estado ou qualidade de excelente, considerada como um valor por muitas organizações, dentre estas escolas e outras instituições de ensino, e como um objetivo em comum a ser alcançado uma vez que pode se tornar uma ferramenta operacional de melhoria contínua e a qualidade de produtos e serviços nas organizações públicas, maximizando o seu valor para todas as partes interessadas.
} 
gias e materiais para o aprimoramento do conhecimento da voz infantil e infanto-juvenil. Estudos de processos de preparação vocal, ensaio e performance em corais infantil e infanto-juvenis e preparação de materiais adequados a tais estudos.

Segundo Jansen, a aptidão musical, como as demais aptidões humanas, é homogeneamente distribuida na totalidade da população independendo de classe social, mas dependendo de recursos e estruturas materiais e qualidade de ensino para o seu pleno desenvolvimento (JANSEN 1997).

O desenvolvimento do canto coral como instrumento essencial na área de Educação Musical, sendo uma atividade musical de baixíssimo custo, é a atividade musical que potencialmente tem condições de reunir simultaneamente, qualidade de ensino, qualidade de execução musical e estagio supervisionado para estudantes e uma ampla rede de atividades sociais para todos os participantes.

A composição original para coral infantil e infanto-juvenil assim como arranjos e adaptações de materiais pré-existentes e suas interfaces com a contemporaneidade, tradição e a literatura musical popular e neofolclórica utilizados neste projeto partem de pressupostos técnico-vocais em um contexto amplo de acesso permitido pela pluralidade de informações e acesso a materiais digitalizados, e, portanto, da adequação vocal de tais materiais aos propósitos pedagógicos - educacionais e ao ensino da música como linguagem. As escolhas de repertório são, portanto realizadas a partir desses pressupostos.

Os objetivos pedagógicos-educacionais tratados neste projeto possuem características comuns desenvolvidas principalmente por 
Dalcroze 3 , Kodály ${ }^{4}$ e Orff,, e que em Boysen 6 e Enevold - na metodologia criada por estas para o ensino da Música pelo Canto Coral Infantil e Infanto-juvenil - a reelaboração de traços fundamentais dos educadores e teóricos acima citados.

Dalcroze na Introdução de Rhythm, Music and Education e no capitulo The place of ear training in musical education de 18987, escreve que faltava aos estudantes de música a coordenação entre olhos, ouvidos, mente e corpo necessária para aprender o repertório - e principalmente para tocar bem, percebendo assim que o primeiro instrumento musical ao qual se deveria educar era o corpo. A Euritmia ${ }^{8}$, termo utilizado por Dalcroze, existe como palavra e como conceito desde a Época Clássica na Crécia. Em sua obra de nome "Kanon", o conceituado escultor de Argos, Polykleitos (440 A.C.), define extensamente o conceito eurythmia como o equilibrio de forças atuantes no corpo humano; eu-rhythmós - o ritmo equilibrado, belo, harmonioso é uma categoria estética oculta das Artes Plásticas. Também o arquiteto romano Vitruv (25 A.C.) utiliza o conceito "euritmia", relacionando-o com a harmonia na arte de construir. Na Época Clássica de Weimar (1786-

\footnotetext{
3 Dalcroze, W. E. Rhythm, Music and Education. Foreword, Preface e Ear training in Musical Education (1898)

${ }^{4}$ Ver também Choksy, L. The Kodály contexto: creating na Environment for Musical Learning 5 Orff, C. Musik für Kinder

${ }^{6}$ Boysen og Enevold - Børnekor- med poesi og bevagelse, Vol 1 - 4

7 Dalcroze, E. Rhythm, Music and Education

http://archive.org/stream/rhythmmusicandeOOrubigoog\#page/n20/mode/2up (acessado em 14.10.2014)

8 For the principle itself and the total method embodying it, another name is needed, and the term "Eurhythmics" has been here coined for the purpose. The originality of the Dalcroze method, the fact that it is a discovery, gives it a right to a name of its own: it is because it is in a sense also the rediscovery of an old secret that a name has been chosen of such plain reference and derivation. Plato, in the words quoted above, has said that the whole of a man's life stands in need of a right rhythm: and it is natural to see some kinship between this Platonic attitude and the claim of Dalcroze that his discovery is not a mere refinement of dancing, nor an improved method of music-teaching, but a principle that must have effect upon every part of life. John W. Harvey in THE EURHYTHMICS OF JAQUES-DALCROZE, http://www.gutenberg.org/files/21653/21653-h/21653-h.htm (acessado em 10.12.2014).
} 
1832) surge novamente o nome Eurythmie, cujo conceito é definido por Herder (1744 - 1803) como a "ordem benfazeja de um centro em relação a dois extremos".?

Dalcroze estuda os elementos da música através do movimento, partindo de três pressupostos básicos:

1 - Todos os elementos da música podem ser vivenciados através do movimento.

2 - Todo som musical inicia-se com um movimento.

3 - Há um gesto para cada som, e um som para cada gesto.

Kodály na Conferência Sobre o Papel da Música na Educação, Universidade da Califórnia em 1966, afirma que:

Temos que educar músicos antes de formar instrumentistas. Uma criança só deve ganhar um instrumento depois que ela já sabe cantar. Seu ouvido vai-se desenvolver somente se suas primeiras noções de som são formadas a partir de seu próprio canto, e não conectadas com qualquer outro estímulo externo visual ou motor. A habilidade de compreender música vem através da alfabetização musical transferida para a faculdade de ouvir internamente. E a maneira mais efetiva de se fazer isto é através do canto (KODÁLY 1966 apud MONTI ).

Kodály, através de uma concepção pedagógica clara, coletou e sistematizou canções folclóricas, criando também arranjos a duas e três vozes, produzindo assim um material pedagógico próprio para implementar e sistematizar o ensino da Música através da voz e especialmente do canto coral com a premissa fundamental de que a música e o canto deviam ser ensinados de forma a proporcionar experiências prazerosas, e não como um exercícios mecânicos e rotineiros, utilizando para tal um material compreensivel e com qualidade

\footnotetext{
9 Ver também $\bigcirc$ que é Euritmia, SAB, Sociedade Antroposófica Brasileira. http://www.sab.org.br/portal/euritmia/9 I-euritmia (acessado em 10.12.2014).
} 
artística. Kodály acreditava que a música tinha que ser para todos; por isso, dedicou-se com determinação a tornar a música uma linguagem compreensivel, tornando a música parte integrante da educação geral.

Kodály utiliza o Dó móvel, onde o solfejo baseado na tônica já introduz, desde cedo, o conceito de função harmônica que, associado de gestos manuais com a altura das notas (manosolfa), conecta um som a um movimento corporal; Kodály utiliza também o sistema que utiliza letras combinadas com o valor rítmico das notas. Boysen e Enevold utilizarão da mesma técnica em ensaios, principalmente para crianças que ainda não aprenderam a ler ov estão em processo de aprendizagem de leitura partituras.

Na proposta de Orff, as atividades lúdicas infantis como cantar, recitar rimas, bater palmas, dançar e percutir são direcionadas ao aprendizado musical e a escrita ocorre após esses aprendizados; o ensino da música ocorre como consequência da experiência - esta sim, o fundamento do processo de aprendizagem musical, sendo que a conscientização é uma consequência do aprendizado ocorrido.

Poemas, rimas, provérbios, jogos, ostinatos, canções e danças usados como exemplos e como material básico podem ser tradicionais, folclóricos ou composições originais. O material falado, declamado ou cantado pode ser acompanhado por palmas, batidas com os pés, baquetas, sinos e instrumentos que ofereçam a possibilidade imediata do fazer musical através da remoção de teclas e placas, tendo com a finalidade a utilização inicialmente da escala pentatônica, posteriormente a escala hexatônica com a inclusão do quarto grau e posteriormente incluindo a sensivel. $\bigcirc$ ensino destina-se a todas as crianças, sem buscar talentos. Há um lugar para criança e cada um contribui no fazer musical de acordo com suas respectivas habilidades e progressos musicais.

Boysen e Enevold ao retomar esses traços fundamentais, e dire- 
ciona-los ao canto coral infantil e infanto-juvenil fundindo-os com uma ampla pesquisa sobre a voz infantil e infanto-juvenil, tornam possivel, através da metodologia que desenvolveram, um alto desempenho técnico e uma grande compreensão musical através de um processo essencialmente lúdico que se inicia com crianças a partir dos cinco anos de idade.

A educação musical através do canto coral inicia-se, na metodologia de Boysen e Enevold, com a consciência do movimento, a interiorização melódica e harmônica através do manosolfa, com a utilização de canons e passos coreográficos, introduzindo o fazer polifônico e a independência melódica em canções a 2 ou mais vozes.

Escutar, perceber e compreender a música interiormente é, portanto, considerada sob essa perspectiva, como a fundação da musicalização. Consideramos aqui a diferença entre ouvir, que ocorre simultaneamente com a recepção dos sons através da audição, e escutar, perceber e compreender que ocorrem através de um processo cognitivo, onde o cérebro confere significância aos sons recebidos através da audição.

Cabe aqui uma breve menção à Sinestesia e a importância da compreensão deste fenômeno como recurso metodológico dentro ensino de Música: sinestesia (do grego ouvaı Onoia: syn - união ou junção e esthesia - sensação) é a relação de planos sensoriais diferentes. Cytowic (1995) e Tornitore (1999) são unânimes em afirmar que o campo de estudos referente à sinestesia só é alargado a partir do desenvolvimento da neurociência e em particular da neuropsicologia, bem como da tomografia computadorizada do cérebro embora o fenômeno no âmbito dos sentidos já tenha sido identificado desde a Grécia Antiga. Cyłowic (idem 1995,) defende que todos nós somos sinestésicos, embora poucos tenham consciência da natureza holística da percepção, observando que a sinestesia é um fenômeno multidimensional e que, segundo o autor, se apresenta em cada ser humano de forma peculiar e diferenciada. As múltiplas interconexões presentes no cérebro atua 
como um sistema de "anéis dentro de anéis", um dado sensório ao penetrar a rede de conexões produz ondulações que se espalham formando círculos concêntricos ativando assim outras sensações, podendo a interconexão dos vários sensos estar adormecida ou ativada. A complexidade do processo de inter-relações, no que se refere às relações do todo e as partes constituintes começa logo que há siste$\mathrm{ma}$, isto é, inter-relações de elementos diversos numa unidade que se toma complexa (una e múltipla). A complexidade sistêmica manifesta-se, sobretudo, no fato de que o todo possui qualidades e propriedades que não se encontram no nivel das partes consideradas isoladas $e$, inversamente, no fato de que as partes possuem qualidades e propriedades que desaparecem sob o efeito das coações organizacionais do sistema A complexidade sistêmica aumenta, por um lado, com o aumento do número e da diversidade dos elementos, e, por outro, com o caráter cada vez mais flexível, cada vez mais complicado, cada vez menos determinista (pelo menos para um observador) das inter-relações (interações, retroações, interferências etc). (MORIN 2005).

\section{O ensino de música como linguagem, a criação e o modelo epistemológico de Qvartrup}

A essência do pensamento filosófico, científico e artístico, que através da assinatura do autor, colocaram as artes em um patamar além da cultura e do culto religioso encontra-se na Grécia pré-socrática. Segundo Fubini (apud TOMÁS, p 28), o universo musical é apenas uma parte para a compreensão da passagem do mito ao logos, da relação entre palavra e pensamento, afastando qualquer julgamento que considere o saber musical como regionalizado ou estrito para tentarmos penetrar no pensamento musical grego. Pensamento semelhante é observado em Jaeger (apud TOMÁs, idem) que destaca que no tocante à cultura (ou na expressão mais adequada, paidéia (educação, e no sentido mais abrangente do termo, cultura geral) o conceito baseia-se em uma perspectiva tal que "nada thes parecia como parte isolada do resto, mas sempre como um todo ordenado em conexão 
viva, na e pela qual tudo ganhava posição e sentido.

Em uma rápida exposição do modelo epistemológico e da sistematização de Qvartrup (apud BERG 20 12)10 no tocante a modelos de ensino e aprendizagem e sua utilização em sociedades cognitivas complexas, tocaremos em quatro níveis de ensino e aprendizado interligados, mas distintos:

O primeiro, denominado por Qvortrup de Estímulo de Aprendizado Direto, são comumente ocorrentes, por exemplo, em classes de aula ou outras formas de transferências, tais como por meios mediáticos, cujos resultados são os conhecimentos factuais e mais facilmente mesuráveis.

O segundo, denominada por Qvortrup de Relevante, é fruto de uma forma de educação que prevê o estímulo dos sistemas de autoaprendizagem individuais ou em grupo e que tem como propósito produzir e repensar o conhecimento.

No terceiro nível, Produção, Qvortrup propõe uma forma de educação e de trabalho inteira e completamente autônoma, a Criação, baseada em conhecimentos profundos adquiridos através dos primeiro e segundo níveis, conhecimentos esses integrados à pesquisa meta-reflexiva, seja esta individual ou em grupo, cujos resultados não podem ser medidos por instrumentos da primeira e segunda categoria, necessitando assim da criação de novos instrumentos de avaliação.

quarto nivel, a que Qvortrup denomina de Evolução Social, refere-se aos pré-requisitos para o conhecimento prévio, que se constituem em um ambiente de conhecimento ou de uma cultura de aprendizagem que não podem ser transferidos através da comunica-

\footnotetext{
10 Para uma leitura mais aprofundada sobre as proposta de Qvortrup, recomenda-se a leitura do artigo de Berg, S. C. (2012). Estratégias de ensino e ferramentas pedagógicas segundo os modelos epistemológicos propostos por Jansen e Qvortrup. Memorandum, 23, 228-235. http://www.fafich.ufmg.br/memorandum/a23/bergol (acessado em 10.09.2014).
} 
ção indivíduo-alvo, mas que agem como o resultado da interação de camadas de comunicação contínua, e que estão intimamente ligados à sociedade, ao meio e às formas de organização de instituições.

Nota-se que o terceiro nivel proposto por Qvartrup possui uma correlação com Heidegger e à Arte como essência indissociável da obra e do autor/artista como uma produção diferenciada e única: a exceção e não a regra. A Arte (exceção) é um distanciamento crítico da cultura (o bem comum) embora necessite de um ambiente de conhecimento ou de cultura prévios.

Cabe aqui ressaltar que o conceito descritivo de cultura, que toma como ponto de partida ideias, valores, regras e normas, e que concebe o conceito de cultura como sendo delimitado às fronteiras (sejam estas de qualquer natureza), e que primam pela manutenção de traços comuns, vem sendo revisto criticamente, uma vez que este não mais se aplica às sociedades complexas sujeitas a redes de novos conhecimentos e que exige socialmente novas formas organizacionais sujeitas a alta produção a velocidades cada vez maiores de produção e propagação. Faz-se, pois necessário um conceito necessariamente dinâmico, capaz de absorver as contradições inerentes à cultura e das relações que se originam nas sociedades cognitivas complexas.

Segundo Morin (2000), o pensamento complexo é essencialmente o pensamento capaz de reunir (complexus: aquilo que é tecido conjuntamente), de contextualizar, de globalizar, mas, ao mesmo tempo, capaz de reconhecer o singular, o individual, o concreto.

No prefácio do livro Introdução ao Pensamento Complexo, Morin destaca dois possiveis fatores que possam desviar as mentes do real entendimento do pensamento complexo. $O$ primeiro se refere ao engano de acreditar-se que a complexidade conduz à eliminação da simplicidade. Segundo Morin (idem), a complexidade surge na falha da simplicidade, mas "integra tudo aquilo que põe ordem, clareza, distinção precisão no conhecimento" (ibidem p. 6). O pensamento com- 
plexo agrega todos os possíveis modos simplificadores de pensar, mas não dá espaço às implicações redutoras, unidimensionais, mutiladoras, enquanto o pensamento simplificador desfaz a complexidade da realidade.

Pensamento complexo busca o conhecimento multidimensional articulando os diferentes campos disciplinares, que aspira a um saber não fragmentado, não redutor, não desmembrado pelo pensamento disjuntivo, que reconhece que qualquer conhecimento está inacabado, incompleto, e oferece a possibilidade de ser questionado, interrogado e reformulado. Portanto "as verdades denominadas profundas, mesmo contrárias umas às outras, na verdade são complementares, sem deixarem de ser contrárias" (ibidem pag.7), uma vez que ao fragmentar determinado conhecimento, isola o que foi separado e oculta possiveis religações.

A Música, por ser a arte do som no tempo (ou do tempo no som), necessita trabalhar especialmente com a memória, que a articula enquanto linguagem que se desenvolve no tempo. A Memória é também um dos elementos fundamentais para qualquer aprendizado. $\bigcirc$ termo memória tem sua origem etimológica no latim e significa a faculdade de reter e lou readquirir ideias, imagens, expressöes e conhecimentos adquiridos anteriormente reportando-se às lembranças, reminiscências. A memória é uma faculdade cognitiva extremamente importante porque forma a base para a aprendizagem. A memória não está localizada em uma estrutura isolada no cérebro; ela é um fenômeno biológico e psicológico envolvendo uma aliança de sistemas cerebrais que funcionam juntos (CARDOSO).

Dentre as várias categorias de memória, duas são importantes para a fundamentação deste projeto:

1 - A memória de curto prazo (ou curta duração), que dura minutos ou horas e serve para proporcionar a continuidade do nosso sentido do presente. 
2 - A memória de longo prazo (ou de longa duração), que estabelece engramas (ou traços duradouros) e dura dias, semanas ou mesmo anos).

Para que a memória de curto prazo se torne permanente, é necessário atenção, repetições e idéias associativas. Se o processo for bem sucedido, a informação será armazenada na memória de longa duração que é mais permanente e tem uma capacidade muito mais ampla. Tanto uma a afirmação correta quanto uma afirmação errônea podem se tornar permanentes (grifo nosso) caso repetidas suficientemente.

Buscamos neste projeto a escrita composicional, organicamente e originalmente criados para que os grupos a que se destina possam, através desses materiais musicais, efetuarem um desenvolvimento técnico-artesanal, poético e musical mais rápido e eficiente. Buscamos também promover a melhoria técnica através de materiais musicais capazes de promover um rápido progresso musical e crescente interesse e dedicação por parte do aluno, assim como na utilização de progressivas dificuldades técnicas no material musical produzido, de modo a favorecer rapidamente a entoação, como descrito abaixo.

A entoação vocal direta ou indiretamente está baseada nos seguintes aspectos: Postura, Respiração, Apoio, balanceamento entre Relaxamento e Tensão, Articulação, Compressão e Formação do som e Ressonância. Somente quando estes elementos estiverem sendo correta e organicamente utilizados, é que se poderá trabalhar tecnicamente com a Entoação.

Erik Christensen (CRISTENSEN 1996) define o timbre como uma dimensão básica da escuta, pertencente à escuta microtemporal, e como qualidade do espectro complexo do som. Como qualidades subsequentes, a altura, como percepção em foco, e a harmonia como qualidade de cor do espectro do som. 
Cabe aqui definir que a entoação dos instrumentos de afinação não-fixa como a voz, cordas e sopros na performance musical em tempo real. Ao contrário de instrumentos como o piano, que são constritos a uma afinação pré-determinada, esses instrumentos assim como a voz, permitem pequenos ajustes de afinação em que técnica e musicalidade se revelam fatores preponderantes.

A composição original para vozes infantis e infanto-juvenis e suas interfaces com a contemporaneidade, tradição e a literatura musical popular e neofolclórica compostas ou arranjadas para este projeto são compativeis com o aparato vocal infantil e infanto-juvenil, permitindo o progresso técnico vocal, o aprendizado da entoação vocal individual e coletiva, e o ensino da linguagem em diversos niveis de complexidade.

\section{Referências}

BERC, S. "Estratégias de ensino e ferramentas pedagógicas segundo os modelos epistemológicos propostos por Jansen e Qvortrup". In Memorandum 23, out/2012. Belo Horizonte: UFMG; Ribeirão Preto: USP, p. 228-235, 2012. Disponivel em http://www.fafich.ufmg.br/memorandum/ a23/bergol (acessado em 10.09.2014).

BOYSEN, P. e ENEVOLD, M. Børnekor - med poesi og bevœgelse, Vol 1 - 4 Dansk Sang: Herning, 2001.

CARDOSO, S. H. Memória: O Que é e Como Melhorá-la http://wum.cerebromente.org.br/nO l/memo/memoria.htm (acessado em 10.12.2014).

COSTA, A. S. "Da relação entre logos e daímon em Heráclito: a escuta como definidora do homem". Em Quatro Ensaios sobre música e filosofia. Ribeirão Preto: Editora Coruja, 2013.

CHOKSY, L; The Kodaly Context. Creating an Environmet for Musical 
Learning. Prentice Hall, 1987.

CHRISTENSEN, E. The Musical Timespace - A Teory of Musical Listening. Aalborg University Press, 1996.

CHRISTENSEN, H. Sangstemmens brug. Copenhague: Wilh. Hansen, 1962. . Drengestemmer i overgangsalderen. Copenhague: Wilh. Hansen, 1961.

CYTOUIC R.E. (1995). Synesthesia, phenomenology \& neuropsychology: a review of current knowledge. In Psyche, 2 (10) http://www.theassc.org/ files/assc/2346.pdf (acessado em 14.11.20|4).

DALCROZE, W. E. Rhythm, Music and Education. Foreword, Preface e Ear training in Musical Education (1898). Disponivel em https://archive. org/stream/rhythmmusiceducaO0jaquiala/rhythmmusice ducaOOjaquiala_divu.txt (acessado em 10.09.20|4).

DALCROZE, U.E The Eurhythmics of Jaques-Dalcroze. E-book 2007. Disponivel em http://www.gutenberg.org/files/2 1653/2 1653-h/2 1653-h.htm (acessado em 14.11.2014).

ENEVOLD, M. Vejviser til bornekor. Copenhague: Wil. Hansen 1993.

FORREST, D. L. Prolongation in the Choral Music of Benjamin Britten. Copyright 2009, David Lamar Forrest. Disponivel em https://repositories. toll.org/ttu-ir/bitstream/handle/2346/1 88 13/Forrest_David_Diss.pdf?sequence $=$ (acessado em 10.09.2014).

HOCSET, Carl - Sangteknikk. Oslo: Quatro AS, 1999.

JORDÃO, Gisele, ALLUCCI, Renata, MOLINA, Sergio, TERAHATA, Adriana (COORDENADORES). A música na escola. ALLUCCI \& ASSOCIADOS COMUNICAÇÕES, São Paulo: 20 12. Disponivel em http://www.amusica- 
naescola.com.br/pdf/AMUSICANAESCOLA.pdf

LÉVY, P. Tecnologias Intelectuais e modos de conhecer: Nós somos o texto. Tradução de Celso Cândido. Disponivel em http://caosmosenet/ pierrelevy/nossomos.html (acessado em 05.03.2013).

LÉVY, P. A Emergencia do Cyberspace e as mutações culturais, em palestra realizada no Festival Usina de Arte e Cultura, promovido pela Prefeitura Municipal de Porto Alegre, em Outubro, 1994. Tradução Suely Rolnik. Revisão da tradução transcrita João Batista Francisco. Disponivel em www.sescsp.org.br/sesc/images/upload/conferencias/35. rtf (acessado em 05.03.2013).

MILLER, R. The structure of Singing. New York: Schirmer, 1986.

MORIN, E. MORIN, Edgar; LE MOICNE, Jean-Lovis. A Inteligência da Complexidade. São Paulo: Petrópolis, 2000.

MORIN, E. Ciência com Consciência. Rio de Janeiro: Bertrand Brasil, 2005. Disponivel em http://ruipaz.pro.br/textos/cienciacomconciencia. pdf (acessado em 14.11.2014).

MONTI, Ednardo Monteiro Conzaga do. CANTO ORFEONICO: a linguagem musical em vozes politicas e educativas. Disponivel em http:// www.periodicos.proped.pro.br/index.php/revistateias/article/view/626 (acessado em 12.11.2014).

RICCIARDI, R, R. "A Música na madrugada do destino - uma poética musical para o século XXI". Em Quatro Ensaios sobre música e filosofia. Ribeirão Preto: Editora Coruja, 2013.

TOMÁS, Lia. Ouvir o Logos: música e filosofia. São Paulo: Editora Unesp, 2002.

TORNITORE, T. On the theory and History of Synaesthesie. Disponivel em 
http://www.rodoni.ch/busoni/pittura/sinestesiaeartesinestetica/articolo3.

html (acessado em 11.11.20/4).

THOMAS K. Lehrbuch der Chorleitung, Vol. 1, 2 e 3. Wiesbaden: Breitkopf \& Hartel, 1949.

WALTHER, Bo Kampmann. "Brincando e Jogando: Reflexões e classificações". In: Teoria Digital. Dez anos do FllE: Festival Internacional de Linguagem Eletrônica. São Paulo: Imprensa Oficial do Estado de São Paulo, 2010. 